\title{
Interleukin-10 expression by real-time PCR and homology modelling analysis in the European sea bass (Dicentrarchus Labrax L.)
}

\author{
Francesco Buonocore $^{\mathrm{a}, *}$, Elisa Randelli, Steve Bird ${ }^{\mathrm{b}}$, Chris J. Secombes ${ }^{\mathrm{b}}$, \\ Angelo Facchiano ${ }^{\mathrm{c}}$, Susan Costantini ${ }^{\mathrm{c}}$, Giuseppe Scapigliati ${ }^{\mathrm{a}}$ \\ a Dipartimento di Scienze Ambientali, Università della Tuscia, 01100 Viterbo, Italy \\ b Scottish Fish Immunology Research Centre, Aberdeen University, AB24 2 TZ Aberdeen, UK \\ c CNR, Istituto di Scienze dell'Alimentazione, I-83100 Avellino, Italy \\ Received 25 January 2007; received in revised form 31 May 2007; accepted 31 May 2007
}

\section{Abstract}

In this paper we investigate the interleukin-10 (IL-10) expression and 3D modelling of the European sea bass (Dicentrarchus labrax L.). IL-10 is a regulatory cytokine that has been intensively studied in mammals and has been found mainly involved in the suppression or deactivation of activated immune responses. The full-length sea bass IL-10 cDNA consists of 1015 bp and is translated in a predicted molecule of 187 amino acids. A multiple alignment of this peptide with other known sequences showed the conservation of fundamental IL-10 family characteristics. Expression analysis by real-time PCR in control fish showed a high basal expression in the head kidney (HK), followed by gut and brain. In vitro treatment of HK leucocytes with LPS showed an intense increase of IL-10 expression at $4 \mathrm{~h}$ and a significant decrease at $24 \mathrm{~h}$, with PHA-L no differences were evidenced. A 3D model for sea bass IL-10 was obtained by accurate homology procedures and putative interaction residues with the IL-10 receptor described. The results suggested that sea bass IL-10 could be involved in anti-inflammatory responses, but further experiments are needed to assess its importance in response to pathogenic agents, vaccinations and immunostimulants.

(C) 2007 Published by Elsevier B.V.

Keywords: Interleukin-10 (IL-10); European sea bass; Dicentrarchus labrax; Expression analysis; Real-time PCR; 3D modelling

\section{Introduction}

Cytokines are potent mediators of immune responses in jawed vertebrates, and in recent years a number of teleost cytokine genes with homology to mammalian genes have been discovered (Scapigliati et al., 2006a,b). Interleukin-10 (IL-10) is a regulatory cytokine, exten-

\footnotetext{
* Corresponding author. Dipartimento di Scienze Ambientali, Università della Tuscia, 01100 Viterbo, Italy. Tel.: +39 0761 357644; fax: +390761357179 .

E-mail address: fbuono@unitus.it (F. Buonocore).
}

sively studied in mammals, mainly involved in the sup- 31 pression or deactivation of activated immune responses 32 (Moore et al., 1993, 2001; Mosmann, 1994). IL-10 is 33 produced by macrophages (Barnes et al., 1992) and by 34 the T-helper $2\left(\mathrm{Th}_{2}\right)$ and T-regulatory $\left(\mathrm{T}_{\mathrm{R}}\right)$ cell subsets 35 (Mosmann and Moore, 1991; Street and Mosmann, 1991; 36 Ding et al., 2003). It plays an important role in in- 37 flammation (Bogdan et al., 1991) by inhibiting some 38 activities of macrophages (Fiorentino et al., 1991; Cunha 39 et al., 1992), and certain cytokine production (de Waal 40 Malefyt et al., 1993). IL-10 exerts its biological activity as 41 an homodimer formed by two non-covalently linked 42 
monomers (Tan et al., 1993) and each IL-10 subunit is stabilised by two intra-chain disulfides bonds (Windsor et al., 1993). The IL-10 gene has been recently discovered in the Fugu genome (Fugu rubripes) (Zou et al., 2003) and the cDNA cloned in different fish species (Savan et al., 2003; Inoue et al., 2005; Zhang et al., 2005; Pinto et al., 2006). From these studies it has emerged that IL-10 in fish is an $\alpha$-helical polypeptide with a deduced molecular size of $18 \mathrm{kDa}$, derived from a gene composed of 5 exons and with significant structural similarities with its homologs in mammals (Zou et al., 2003). Moreover, its expression was up-regulated following intra-peritoneal injection of UV-killed Photobacterium damselae ssp. piscicida and seems involved in the resolution of inflammatory responses (Pinto et al., 2006). Therefore, it is interesting to determine if we have in sea bass the presence of an IL-10 dependent signal pathway to counteract the actions of pro-inflammatory factors, especially for its implication in response to pathogenic agents, vaccinations and immunostimulants.

In this work we studied the IL-10 expression by realtime PCR in sea bass (Dicentrarchus labrax) to further assess its implication and important role during antiinflammatory processes. Moreover, we investigated sea bass IL-10 3D structure by homology modelling and analysed the putative interaction residues with the IL-10 receptor.

\section{Materials and methods}

\subsection{Fish and leucocytes}

Outbred mixed sex sea bass $(178 \pm 37 \mathrm{~g})$ used in this work were purchased from a local fish farm (Nuova Azzurro, Civitavecchia, RM). All buffers and solutions used in handling fish cells were brought to $355 \mathrm{mOsm} / \mathrm{kg}$ with $2 \mathrm{M} \mathrm{NaCl}$. Fish were lethally anaesthetised with $1 \mathrm{~g} /$ 1 of benzocaine (Sigma), and $2 \mathrm{ml}$ of blood per fish was drawn from the caudal vein using HBSS-heparin. Whole 78 blood from individual fish was washed twice in HBSS- 79 heparin (Gibco), resuspended in $8 \mathrm{ml}$ of the same solution 80 and loaded over 1.04 and $1.07 \mathrm{~g} / \mathrm{cm}^{3}$ Percoll gradients as 81 previously described (Scapigliati et al., 2001) to obtain 82 peripheral blood leucocytes (PBL). After centrifugation 83 (30 min at $840 \mathrm{~g}$ ) at $4^{\circ} \mathrm{C}$, cells at the interface between the 84 two densities were collected, washed twice with HBSS 85 (10 min at $680 \mathrm{~g}$ ) at $4{ }^{\circ} \mathrm{C}$, and used. The following organs 86 and tissues were removed and placed in cold HBSS: head 87 kidney (HK), spleen, liver, gills, gut, thymus and brain. 88 Cells were obtained by teasing organs (excluding HK, 89 gills and gut) through a 100- $\mu \mathrm{m}$ nylon mesh in HBSS and 90 collecting the pelleted cells after two washes at $680 \mathrm{~g}$ in 91 cold PBS. For HK, gills and gut cells were loaded and 92 centrifuged over Percoll gradients as above to obtain the 93 leukocyte enriched fraction. Cell viability of leukocytes 94 was determined by counting in a haemocytometer with 95 Trypan blue.

\subsection{Sea bass IL-10 cloning}

97

Two primers (IL10FR and IL10RV, see Table 1) cor- 98 responding to highly conserved regions of known IL-10 99 genes were used for RT-PCR on total RNA extracted with 100 Tripure (Roche) solution from juvenile sea bass (150 $\mathrm{g}$ of 101 weight) gut cells obtained following the procedures de- 102 scribed above. For cDNA synthesis, $1 \mu \mathrm{g}$ of total RNA 103 and $0.5 \mu \mathrm{g}$ of random primers $\left[\mathrm{pd}(\mathrm{N})_{6}\right]$ were used in each 104 reverse transcription reaction in a total volume of $50 \mu \mathrm{l} .105$ Reactions were conducted using the Mastercycler per- 106 sonal (Eppendorf). The cycling protocol was one cycle of 107 $94^{\circ} \mathrm{C}$ for $5 \mathrm{~min}, 35$ cycles of $94^{\circ} \mathrm{C}$ for $45 \mathrm{~s}, 55^{\circ} \mathrm{C}$ for $45 \mathrm{~s}, 108$ $72^{\circ} \mathrm{C}$ for $45 \mathrm{~s}$, followed by one cycle of $72^{\circ} \mathrm{C}$ for $10 \mathrm{~min} .109$ PCR products $(15 \mu \mathrm{l})$ were visualised on $1 \%(\mathrm{w} / \mathrm{v})$ aga- 110 rose gels containing ethidium bromide $(10 \mathrm{ng} / \mathrm{ml})$ using 111 hyperladder IV (Bioline) as size marker. Controls for the 112 presence of DNA contamination were performed using 113

Table 1

Oligonucleotides and primers used for cDNA cloning and real-time PCR

\begin{tabular}{|c|c|c|}
\hline Primer & Sequence & Function \\
\hline IL10FR & 5'-TGCTGCTCCTTCGTGGAGGGCTTCCC-3' & Cloning initial sea bass IL-10 sequence \\
\hline IL10RV & 5'-CCAGCTCCCCCATGGCTTTATA-3' & \\
\hline Oligo-dT adaptor primer & $5^{\prime}$-CTCGAGATCGATGCGGCCGCT $15^{-3^{\prime}}$ & $3^{\prime}$ RACE-PCR \\
\hline SB10FR & 5'-CAGATGGAGAGTAAAGGTC-3' & “ \\
\hline Oligo-dG & 5'-GGGGGGIGGGIIGGGIIG-3' & $5^{\prime}$ RACE-PCR \\
\hline SB10RV & 5'-GAGTGATGTCACCAGATG-3' & “ \\
\hline RTACTFR2 & 5'-ATGTACGTTGCCATCC-3' & Real-time PCR for sea bass $\beta$-actin \\
\hline RTACTRV2 & 5'-GAGATGCCACGCTCTC-3' & “ \\
\hline RTIL10SBAFR & 5'-ACCCCGTTCGCTTGCCA-3' & Real-time PCR for sea bass IL-10 \\
\hline RTIL10SBARV & 5'-CATCTGGTGACATCACTC-3' & “ \\
\hline
\end{tabular}

$\mathrm{I}$ in the oligo-dG primer is referred to inosine. 
the RNA samples as template. DNA amplified by PCR was purified using the QIAquick Gel Extraction Kit (QIAgen), inserted into the pGEM-T Easy vector (Promega) and transfected into competent JM109 Escherichia coli cells. Plasmid DNA from at least four independent clones was purified using the Wizard Plus SV Minipreps DNA Purification System (Promega) and sequenced using MWG DNA Sequencing Services. Sequences generated were analysed for similarity with other known sequences using the FASTA (Pearson and Lipman, 1988) and BLAST (Altschul et al., 1990) programs and multiple alignments were made with CLUSTAL W (Thompson et al., 1994).

Further primers were designed against the initial sea bass IL-10 sequence for $5^{\prime}$ - and $3^{\prime}$-rapid amplification of cDNA ends (RACE)-PCR (SB10FR and SB10RV, see Table 1 ). cDNA was synthesised from total gut RNA with the First-strand cDNA Synthesis kit (Amersham Pharmacia) following the manufacturer's instructions. For 3' RACE-PCR, cDNA was transcribed using an oligo-dT adaptor primer (see Table 1). PCR was performed with the SB10FR primer and the oligo-dT adaptor primer. For 5' RACE-PCR, cDNA was transcribed from total RNA using the oligo-dT primer, treated with E. coli RNase H (Promega), purified using a PCR Purification Kit (QIagen), and tailed with poly(C) at the $5^{\prime}$ end with terminal deoxynucleotidyl transferase (TdT, Promega). PCR was performed with SB10RV primer and an oligo$\mathrm{dG}$ primer (see Table 1). Sequencing and similarity searches were as described above.

The obtained cDNA sequences were analysed for the presence of a signal peptide, using SignalP software (Nielsen et al., 1997), and for N- (with the NetNGlyc 1.0 Server) and O-linked glycosylation sites (Julenius et al., 2005). A phylogenetic tree was constructed by the "neighbour-joining" method using CLUSTALW (Thompson et al., 1994) and PHYLIP packages (Felsenstein, 1985; Saitou and Nei, 1987) on full-length amino acid sequences and bootstrapped 10000 times (Felsenstein, 1985).

\subsection{Basal IL-10 expression analysis}

To study the IL-10 basal expression, five sea bass (178 \pm $37 \mathrm{~g}$ ) were sampled and leucocytes from different tissues obtained as described above. Total RNA was isolated from each tissue separately with Tripure (Roche) following the manufacturer's instructions, resuspended in DEPC treated water and used for real-time quantitative PCR without pooling the samples coming from the different fishes. Controls for the presence of DNA contamination were performed using the RNA samples as template and using $\beta$-actin primers that bracket an intron.
For reverse transcription, the BioScript RNase H 164 minus (Bioline) enzyme was used with the following 165 protocol: $2 \mu \mathrm{g}$ of total RNA was mixed with $1 \mu \mathrm{l}$ of 166 random hexamer $(0.2 \mu \mathrm{g} / \mu \mathrm{l}$; Amersham Pharmacia) and 167 nuclease free water was added to a final volume of $12 \mu 1.168$ This mixture was incubated at $70{ }^{\circ} \mathrm{C}$ for $5 \mathrm{~min}$ and then 169 cooled on ice. Successively, $0.4 \mu 1$ of a reaction mix 170 containing $100 \mathrm{mM}$ dNTPs (25 mM each; Promega), 171 $4 \mu 1$ of $5 X$ Reaction buffer, nuclease free water to a final 172 volume of $19.75 \mu \mathrm{l}$ and $0.25 \mu \mathrm{l}$ of BioScript at $200 \mathrm{u} / \mu 1173$ were added and the solution incubated at $25{ }^{\circ} \mathrm{C}$ for 174 $10 \mathrm{~min}$ and then at $37^{\circ} \mathrm{C}$ for $60 \mathrm{~min}$. Finally, the 175 reaction was stopped by heating at $70^{\circ} \mathrm{C}$ for $10 \mathrm{~min} . \quad 176$

The expression level of IL-10 was determined with a 177 Mx3000PTM real-time PCR system (Stratagene) equip- 178 ped with version 2.02 software and using the Brilliant 179 SYBR Green Q-PCR Master Mix (Stratagene) follow- 180 ing the manufacturer's instructions, with ROX as in- 181 ternal passive reference dye. The reference dye is not 182 reactive during real-time PCR and therefore can be 183 used to normalize slight differences in the volume of the 184 added real-time PCR reaction, transparency of the plas- 185 tic caps and other sources of well-to-well differences. 186 Specific PCR primers were designed for the amplifica- 187 tion of about $200 \mathrm{bp}$ products from both IL-10 and 188 $\beta$-actin, used as a house-keeping gene. The primers were: 189 RTIL10SBAFR and RTIL10SBARV, RTACTFR2 and 190 RTACTRV2, respectively (see Table 1). Approximately 191 20 ng of cDNA template was used in each PCR reaction. 192 The PCR conditions were $95^{\circ} \mathrm{C}$ for $10 \mathrm{~min}$, followed by 193 35 cycles of $95^{\circ} \mathrm{C}$ for $45 \mathrm{~s}, 52{ }^{\circ} \mathrm{C}$ for $45 \mathrm{~s}$ and $72{ }^{\circ} \mathrm{C}$ for 194 $45 \mathrm{~s}$. Triplicate reactions were performed for each tem- 195 plate cDNA and the template was replaced with water in 196 all blank control reactions. Each run was terminated with a 197 melting curve analysis which resulted in a melting peak 198 profile specific for the amplified target DNA. The analysis 199 was carried out using the endpoints method option of the 200 Mx3000Ртм software that causes the collection of the 201 fluorescence data at the end of each extension stage of 202 amplification. A relative quantitation has been performed, 203 comparing the levels of the target transcript (IL-10) to a 204 reference transcript (calibrator, the tissue with the lowest 205 IL-10 expression, in this case the thymus). The expression 206 level of the gene of interest (IL-10) in the calibrator is 207 defined as 1.0. A normalizer target ( $\beta$-actin) is included to 208 correct for differences in total cDNA input between sam- 209 ples. The quantitative experiment is based on threshold 210 cycle $(\mathrm{Ct})$ determination, defined as the cycle at which a 211 statistically-significant increase in fluorescence (above 212 background signal) is detected. The results are expressed 213 as the mean $\pm \mathrm{SD}$ of the results obtained from the five 214 considered fishes. The real-time PCR products from the 215 
different tissues were examined successively by agarose gel electrophoresis to investigate their specificity and size.

\subsection{In vitro expression analysis}

The in vitro expression of IL-10 was studied using different stimulating conditions on HK leucocytes from five fishes as above.

In the first stimulation, HK leucocytes were adjusted to $1 \times 10^{5}$ cells $/ \mathrm{ml}$ and incubated at $18{ }^{\circ} \mathrm{C}$ for $4 \mathrm{~h}$ and $24 \mathrm{~h}$ with $5 \mu \mathrm{g} / \mathrm{ml}$ of lipopolysaccharide (LPS from E. coli 0127:B8, Sigma) in PBS or with PBS for the same time points (control).

In the second stimulation, HK leucocytes were adjusted to $1 \times 10^{5}$ cells $/ \mathrm{ml}$ and incubated at $18{ }^{\circ} \mathrm{C}$ for $4 \mathrm{~h}$ and $24 \mathrm{~h}$ with $1 \mu \mathrm{g} / \mathrm{ml}$ of lectin from Phaseolus vulgaris Leucoagglutinin (PHA-L from Sigma) in PBS or with PBS for the same time points (control).

Total RNA was isolated with Tripure (Roche) following the manufacturer's instructions, resuspended in DEPC treated water and used for real-time quantitative PCR without pooling the samples coming from the different fishes. The primers used are described in Table 1. Realtime PCR conditions were as described above, except that the calibrator for this experiment was the $0 \mathrm{~h}$ control.

Data were expressed as the mean $\pm \mathrm{SD}$ of the results obtained from the five considered fishes and the differences from the control at the same time have been considered significant if $p<0.05$ using the standard student $t$ test to analyse the significance.

\subsection{Protein modeling}

Protein sequences used in modelling refer to the following EMBL entries: seabass IL-10, AM268529; human IL-10, M57627 (UniProt: P22301). The threedimensional model of the sea bass IL-10 was created according to the homology modelling strategy and using the template model of human IL-10 (PDB code: 1ILK) (Zdanov et al., 1995).

As the sequence identities between the sea bass protein and the human homologous template were lower than $30 \%$, we used an accurate procedure to search for the best alignment of sequences, already used and described in our previous works (Facchiano et al., 2001; Marabotti et al., 2004; Scapigliati et al., 2004; Costantini et al., 2005; Buonocore et al., 2006; Facchiano et al., 2006) and also in agreement with the rules recently reviewed (Wallner and Elofsson, 2005) to improve the quality of the modeling results. The search for sequence similarity within databases was performed with the BLAST program (Altschul et al., 1990). The alignment of the protein sequences was made with CLUSTALW program (Thompson et al., 1994) 264 and a few manual refinements were added to account 265 for the position of secondary structures. The program 266 MODELLER (Sali and Blundell, 1993) implemented in 267 the Quanta molecular simulation package (Accelrys, San 268 Diego, CA) was used to build 10 full-atom models by 269 setting 4.0 Angstrom as RMS deviation among the struc- 270 tures of the templates and fully optimized models, with 271 multiple cycles of refinement with conjugate gradient 272 minimization and molecular dynamics with simulated 273 annealing. To select the best model among those obtained, 274 PROCHECK program (Laskowski et al., 1993) was used 275 to evaluate the stereochemical quality of the models 276 and their structural packing quality and ProsaII program 277 (Sippl, 1993) to check the fitness of sequence to structure 278 and to assign a scoring function. Secondary structures 279 were assigned by the DSSP program (Kabsch and Sander, 280 1983). Search for structural classification was performed 281 on CATH database (Orengo et al., 1997; Pearl et al., 282 2000).

The atomic coordinates of the human dimer were built 284 operating the symmetry transformations on the atoms of 285 monomer reported in the PDB file by using the tool "Build 286 Crystallographic Symmetry" implemented in SwissPdb- 287 Viewer software (Guex and Peitsch, 1997). The "Protein- 288 Protein Interaction Server" (Jones and Thornton, 1996) 289 and the program NACCESS (Hubbard et al., 1991) were 290 used to identify the amino acids at the protein-receptor 291 interface in the crystallographic complexes. Molecular 292 superimposition, RMSD values and figures were obtained 293 with the InsightII package (Accelrys, Inc., San Diego, 294 CA, USA).

\section{Results}

\subsection{Sea bass IL-10 cloning}

297

PCR with primers IL10FR and IL10RV gave a product 298 of the expected size (406 bp) that when sequenced had 299 good homology for other known IL-10 sequences (data 300 not shown). 5'-RACE-PCR performed with SB10RV 301 (based on the initial 406 bp sequence) and oligo-dG primer 302 gave a product of about $530 \mathrm{bp}$ that contained the $5^{\prime}$-end of 303 the gene. 3'-RACE-PCR performed with SB10FR (based 304 on the initial $406 \mathrm{bp}$ sequence) and oligo-dT adaptor 305 primer gave a product of about $400 \mathrm{bp}$ that contained the 306 $3^{\prime}$-end of the gene. The full-length nucleotide sequence 307 (EMBL accession number AM268529) is comprised of 308 $1015 \mathrm{bp}$ obtained from the three overlapping products. It 309 was translated in one reading frame to give the entire IL-10 310 molecule containing 187 amino acids, with a predicted 22311 amino acid signal peptide, a 143 bp 5'-UTR and a 313 bp 312 
$313 \quad 3$ '-UTR. Finally, the 3 '-UTR contained a polyadenylation

314 signal (AATAAA) 17 bp upstream of the poly(A) tail and

315 three mRNA instability motifs (ATTTA).
A multiple alignment of the predicted translation of the 316 IL-10 sea bass molecule with other known IL-10 sequences 317 was assembled (Fig. 1) to investigate the conservation of 318 human

mouse

pig

cow

chicken

pufferfish

takifugu

sea bass

silver carp

carp

zebrafish

trout

MHS- -SALLCCLVLLTGVRASPGQGTQSEN-SCTHFP - - - - - - - - - GNLPNMLRDL 44 MPG - -SALLCCLLLLTGMRISRGQYSREDN-NCTHFP - - - - - - - - VGQSHMLLEL 44 MPS - - SALLYCLIFLAGVAAS - - - IKSEN-SCIHFP - - - - - - - - TSLPHMLREL 40 MANVIYVVLALNILLSQIHVSNPYCTSCSHRDCTEDEDQKQLCEGGSGGLGSLPHMLREL 60 MQT - - CCQALLLLLAACTLP - - - AHCLEPTCLHFS - - - - - - - ELLPARLREL 40 MPGRT -LLSVLLL - - LSSSCAVWCATLCNNRCCSFLEG - - - - - - - - - - FPARLKVL 43 MTPGS-LLSVLLL - - LCCACTVWCAALCNNRCCSFVEG - - - - - - - - - FPARLKML 43 MTPRSLLLSILVV--LSFFCTVWCSPMCNNQCCRFVEG---- - - - - - -FPGMLRQL 44 MIFSRVIFSALVM-LLLSESAQCRRVDCKSECCSFVEG - - - . - . - . - FPVRLKEL 45 MVFSGVILSALVM - FLLSDSAQCRRVDCKTDCCSFVEG - - - - - - - - - FPVRLKEL 45 MIFSGVILSALLT-LLLCDCAQSRRVECKTDCCSFVEG-- - - - - - - - - FPLRLREL 45 MSPCSLLLSLLLAAALQCEHAQCRRVPCSDRCCSFVEG - - - - - - - - - - FPVRLKEL 46 *

A

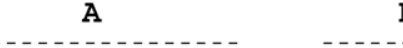

RDAFSRVKTFFQMKD-QLDNLLLKESLLEDFKGYLGCQALSEMIQFYLEEVMPQAENQDP 103 RTAFSOVKTFFOTKD-OLDNILLTDSLMODFKGYLGCOALSEMIOFYLVEVMPOAEKHGP 103 RAAFGPVKSFFQTKD-QMGDLLLTGSLLEDFKGYLGCQALSEMIQFYLEDVMPKAESDGE 99 RAAFGKVKTFFQMKD-QLHSLLLTQSLLDDFKGYLGCQALSEMIQFYLEEVMPQAENHGP 119 RVKFEEIKDYFOSRDDELNIOLLSSELLDEFKGTFGCOSVSEMLRFYTDEVLPRAMOTST 100 RENYSNIREYYEAND-DLDLVLIDOSIVESFKTPFACHVMDGILKLYLDSVLPRALASVT 102 RENYSQIRDYYEAND-DLDIVLLDQSIVDTFKTPFACHLMDGILRFYLDSVLPRALATVT 102 RADFTEIQDFYEAND-DLDAALLDQTVEDTLKTPFACHAINSILEFYLSTVLPTAMAGVT 103 RSAYREIORFYESND-DLEP - LLNENVQONINSPYGCHVMNEILRFYLETILPTAVQKNH 103 RSAYREIQNFYESND-DMEP-LLDENVQQNINSPYGCHVMNEILRFYLDTILPTAVQKDH 103 RSAYKEIQKFYESND-DLEP-LLNEDIKHNINSPYGCHVMNEILHFYLETILPTALQKNP 103 RTAFSTIRDYYEAND-ELETSLLDEGILHHLKSPVGCHAMDSILKFYLDTVLPTAMNNRT 105

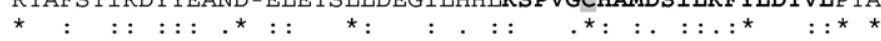

\section{D}

D- - - IKAHVNSLGENLKTLRLRLRRCHRFLPCENKSKAVEQVKNAFNKLQEKGIYKAMS 159 E- - - IKEHLNSLGEKLKTLRMRLRRCHRFLPCENKSKAVEQVKSDFNKLQDQGVYKAMN 159 D- - - IKEHVNSLGEKLKTLRLRLRRCHQFLPCENKSKAVEEVKSAFSKLQERGVYKAMG 155 D- - - IKEHVNSLGEKLKTLRLRLRRCHRFLPCENKSKAVEKVKRVFSELQERGVYKAMS 175 S- - - HQQSMGDLGNMLLGLKATIRRCHRFFTCEKRSKAIKQIKETFEKMDENGIYKAMG 156 VETRDLQPHVESIQQILDQLKTEVNNCKHFFACKNQFDMNTLTSAYTQAMQEKGLFKAMG 162 AETRNLKPHVESIQQIFDQLKIEVTNCKHYFACKNRFDINVLNSTYTK-MEDKGLYKAMG 161 EDTKDLKPHMESIOOIFDOLKSDVTRCRHYFKCKHHFDINTLNSTYTO-MESKGLYKAMG 162 L---HPKTPIDSIGS IFQDLKRDMVKCRKYFSCKNPFEFATIKNSYEK-MKEKGVYKAMG 159 L---HSKTPINS I GNI FQDLKRDMRKCRNYFSCQNPLEIASIKNSYEK-MKEKGVSKAMG 159 LK--HSTTPIDSIGNIFQELKRDMVKCKRYFSCQNPFEVNSLKNSYEK-MKEKGVYKAMG 160 QNNNDFKSPIDSIGNIFHELKKEIVQCRNYFSCKKPFDINEFISSYEK-MQDKGLYKAMG 164

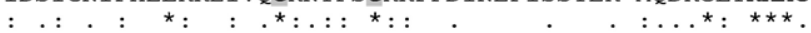

F

\begin{tabular}{|c|c|}
\hline & \\
\hline EFDIFINCIEAYMMIKMKS-- - - - & 178 \\
\hline EFDIFINYIEAYMTMKMRKN- - - - & 175 \\
\hline EFDIFINYIETYMT------- - - & 189 \\
\hline EFDIFINYIEEYLLMRRRK-- - - - & 175 \\
\hline ELDLLFNYIEMYMSSKTHRNKA- - - & 184 \\
\hline ELDLLFNYIENYLASKRRRNVA--- & 183 \\
\hline ELGLLFNYIETYMASKQHRNHAASV & 187 \\
\hline ELDMLFKYIEQYLASKREKH - - - - - & 179 \\
\hline ELDILFKYIEQYLASKRVKHL - - - - & 180 \\
\hline ELDLLFRYIEQYLASKRVKH - - - - - & 180 \\
\hline ELDLLFNYIEEYLVSKRRKH--- - - & 184 \\
\hline
\end{tabular}

Fig. 1. Alignment of the predicted sea bass IL-10 amino acid sequence with other known IL-10 molecules. Identical (*) and similar (. or :) residues identified by CLUSTAL W are indicated. The conserved cysteine residues and the IL-10 family signature motifs are gray and bolded. The six $\alpha$-helical domains (A-F) predicted in human IL-10 are marked by hyphens. In the sea bass IL-10 sequence the predicted signal peptide is in italics and the putative $N$-glycosilation site is underlined and bolded. Accession numbers: Homo sapiens (human) U16720; Mus musculus (house mouse) M37897; Sus scrofa (pig) L20001; Bos bovis (cow) AY186733; Gallus gallus (chicken) NP_001004414; Tetraodon nigroviridis (spotted green puffer fish) AJ544898; Takifugu rubripes (Fugu rubripes) AJ539537; Hypophthalmichthys molitrix (silver carp) DQ058295; Cyprinus carpio (common carp) AB110780; Danio rerio (zebrafish) AY887900; Oncorhynchus mykiss (rainbow trout) AB118099. 
amino acid residues involved in the structural domains found within IL-10s. The putative crystal structure deduced from human recombinant IL-10 showed the presence of six helices (A-F, Fig. 1) with approximately $85 \%$ of the residues in $\alpha$-helical conformation (Zdanov et al., 1995) and revealed that the molecule is likely to exist in solution as a tight dimer made of two inter-penetrating subunits. The helices with the highest degree of homology between the human and fish sequences are the C-helix and the F-helix that contain the IL-10 family signature motifs (Inoue et al., 2005). Moreover, it is noteworthy to observe that some of the amino acid residues found in helices are well conserved only between the fish sequences, especially in the $\mathrm{A}, \mathrm{C}$ and $\mathrm{F}$ stretches.

The sea bass IL-10 molecule contains four cysteine residues (Cys-30, 80, 130 and 136) that are conserved in all IL-10 vertebrate sequences showed in the alignment, although two extra-cysteine residues (Cys-26 and 31) are present in the $\mathrm{N}$-terminal region and conserved in all fish sequences but not in mammals. The structure of human IL-10 is stabilized by two intra-molecular disulfide bridges that join helices $\mathrm{A}$ and $\mathrm{C}$ to helix D (Windsor et al., 1993; Zdanov et al., 1995) and the involved cysteine residues are the ones conserved in all IL-10 sequences. A unique putative $\mathrm{N}$-glycosylation site has been found in the sea bass IL-10 sequence (Asn146, Ser147, Thr148) in the

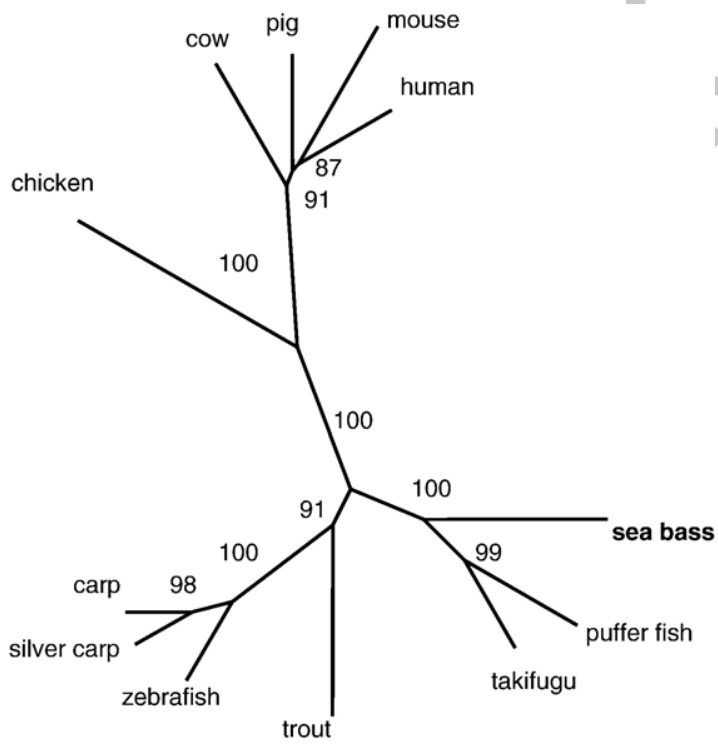

0.1

Fig. 2. Unrooted phylogenetic tree showing the relationship between sea bass IL-10 with other known IL-10 molecules. The tree was constructed by the "neighbour-joining" method and was bootstrapped 10,000 times. The bar (0.1) indicates the genetic distance.

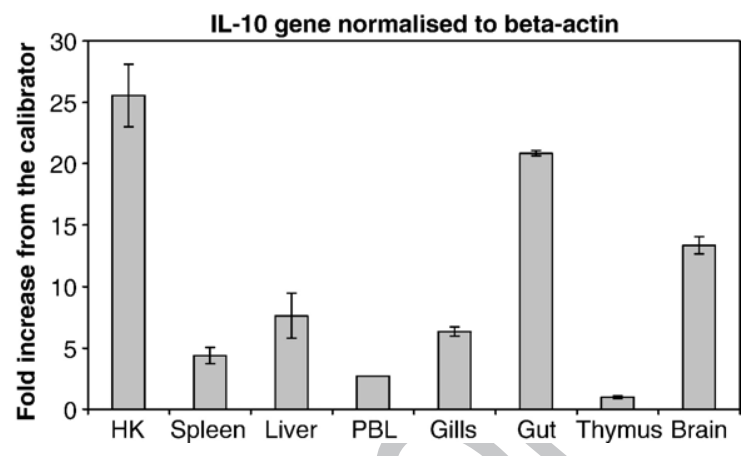

Fig. 3. IL-10 basal expression in different tissues. IL-10 mRNA levels were expressed as a ratio relative to $\beta$-actin levels in the same samples after realtime PCR analysis using the tissue with the lowest expression as calibrator.

same position found in the Fugu molecule but different 345 from the one found in trout, although glycosylation seems 346 not to be required for biological activity.

Phylogenetic analysis (Fig. 2) conducted using amino 348 acid sequences showed that sea bass IL-10 grouped with 349 other known teleost sequences close to Tetraodon and 350 Fugu. Moreover, the presence of three different clusters 351 formed by the mammalian, the avian and the fish IL-10 352 sequences was quite evident. The positions in the tree 353 were all supported by high bootstrapping values.

3.2. IL-10 basal expression levels

The expression analysis of IL-10 in organs and tis- 356 sues of un-stimulated sea bass is shown in Fig. 3. Real- 357 time PCR products were loaded on agarose gels to 358 exclude the formation of non-specific amplicons and 359 single bands of the expected sizes were obtained. More- 360 over, to take into consideration the individual genetic 361 variability five different fish were sampled and analysed 362 separately. The highest IL-10 expression was detected 363 in HK, followed by gut. Lower IL-10 mRNA levels 364 were observed in brain, liver, gills, and spleen. PBL and 365 thymus showed the lowest expression levels.

\subsection{In vitro expression analysis}

To investigate whether IL-10 expression level could 368 be modulated with LPS and PHA-L, in vitro stimulation 369 of HK leucocytes for a short (4 h) and a longer (24 h) 370 time was studied, RNA was extracted from the HK 371 leucocytes of five individuals analysed separately. Real- 372 time PCR products were loaded on agarose gels and 373 single bands of the expected sizes were obtained as 374 above. The results are shown in Fig. 4. Using LPS 375 (Fig. 4A), a dramatic increase of IL-10 expression was 376 detected at $4 \mathrm{~h}(p<0.05)$, whereas at $24 \mathrm{~h}(p<0.05)$ it 377 
A

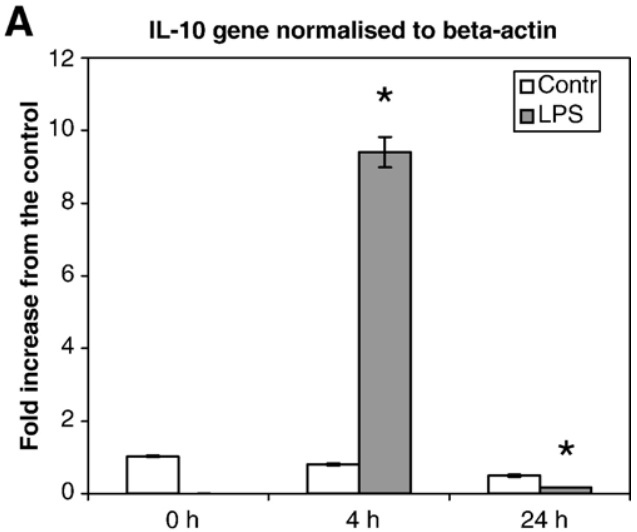

B

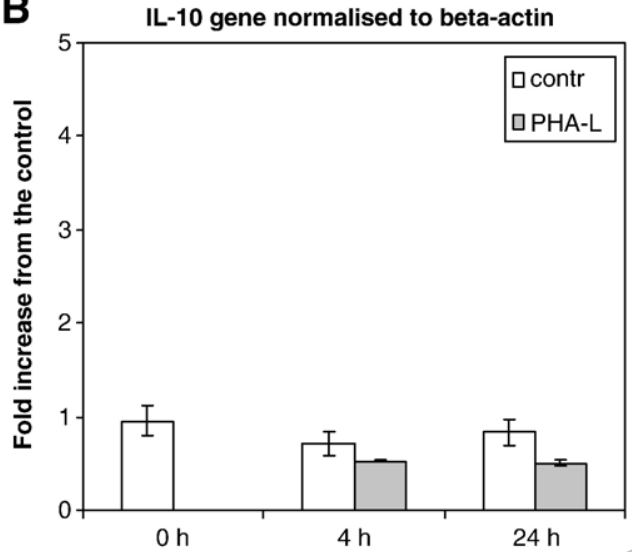

Fig. 4. In vitro sea bass IL-10 expression analysis. (A) LPS: IL-10 mRNA levels expressed as a ratio relative to $\beta$-actin levels in the same samples after real-time PCR analysis of HK leucocytes stimulated with PBS (control) and with $5 \mu \mathrm{g} / \mathrm{ml}$ LPS for 4 and $24 \mathrm{~h}$ and normalised against the non-stimulated controls. (B) PHA: IL-10 mRNA levels expressed as a ratio relative to $\beta$-actin levels in the same samples after real-time PCR analysis of HK leucocytes stimulated with PBS (control) and with $1 \mu \mathrm{g} / \mathrm{ml}$ PHA-L for 4 and $24 \mathrm{~h}$ and normalised against the non-stimulated controls. Controls for 4 and $24 \mathrm{~h}$ of incubation without LPS and PHA-L are also shown in the graphs. Data were expressed as the mean $\pm \mathrm{SD}$ and asterisks indicates when $p \leq 0.05$ with respect to their control.

was lower than the control. When using PHA for in vitro 378 treatment (Fig. 4B), a decrease was observed both at $4 \mathrm{~h} 379$ and $24 \mathrm{~h}$, although being not statistically significant. $\quad 380$

\subsection{D modelling of sea bass IL-10}

The sequence of sea bass IL-10 has been analyzed 382 with the BLAST program to find similar sequences in 383 databases and perform structure predictions. The search 384 in the non-redundant database has evidenced that this 385 protein is significantly similar ( $E$-value less than $\left.10^{-12}\right) 386$ to 34 protein sequences, from different organisms, de- 387 fined as "IL-10" (data not shown). The percentage of 388 sequence identity between IL-10 in sea bass and the other 389 sequences ranged from $67 \%$ to $44 \%$ for teleost fish 390 sequences, and from $30 \%$ to $27 \%$ for mammal se- 391 quences. The search also found the experimental three- 392 dimensional structure of human IL-10 (PDB code: 1ILK) 393 (Zdanov et al., 1995), that could be used for comparative 394 modeling. The BLAST pairwise alignment between sea 395 bass and human sequences evidenced amino acid iden- 396 tity lower than the threshold value of $30 \%$. This level of 397 sequence identity requires a careful procedure to build a 398 3D model of the protein by comparative modeling. $\quad 399$

Multiple alignment of the IL-10 sequences was per- 400 formed with the CLUSTALW program and starting from 401 this alignment (Fig. 5), we created ten structural models 402 for the sea bass IL-10 28-187 region. The best model was 403 chosen evaluating the scoring functions with ProsaII 404 program (Sippl, 1993). The stereo chemical quality in 405 human and sea bass models was evaluated using the 406 PROCHECK program (Laskowski et al., 1993) and the 407 percentage of residues in most favoured regions was 408 $95.0 \%$ in human structure and $94.6 \%$ in the chosen model 409 for sea bass IL-10. The quaternary structure of IL-10 410 dimer was assembled by superimposing two equal sea 411 bass (monomers) chains to those in human dimer. In Fig. 6412

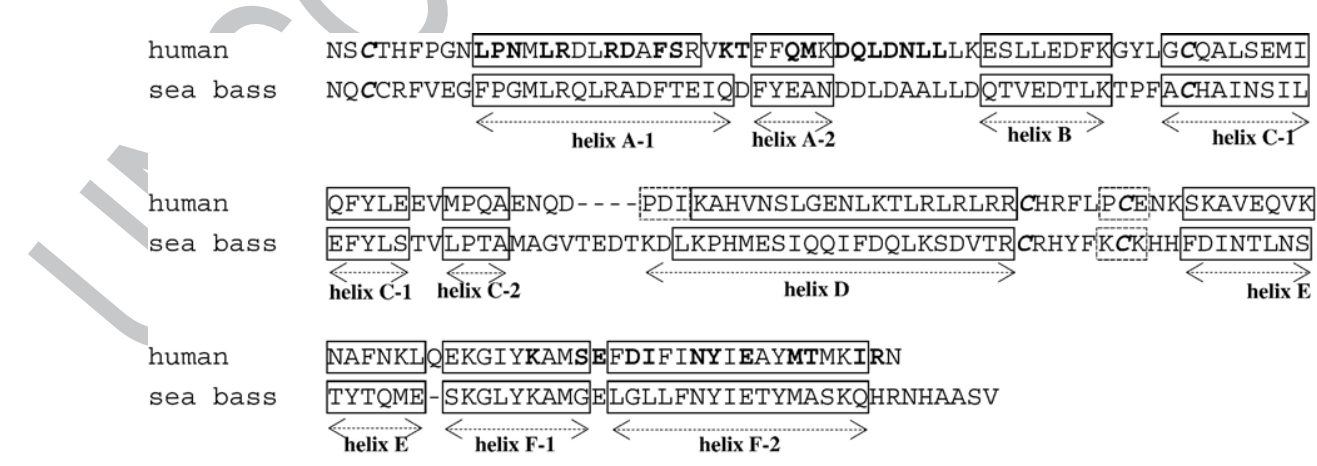

Fig. 5. Primary and secondary structures of sea bass IL-10, aligned with human IL-10 as for the modelling procedure using CLUSTAL W. The interaction residues of IL-10 with IL-10R are reported in bold. The cysteine is evidenced in bold/italics. The six helices found in the IL-10 structures are marked with arrows. Alpha helices are indicated with continuous line boxes and $3_{10}$ helices with dashed line boxes. 

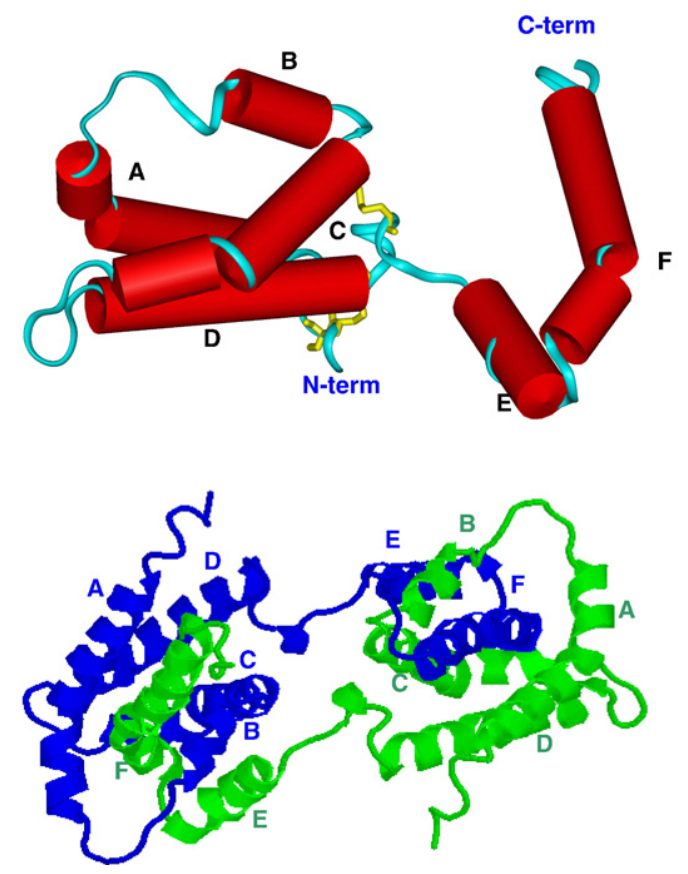

Fig. 6. The monomer and the dimer of seabass IL-10. (a) Backbone ribbon of monomer of sea bass IL-10 obtained by homology modelling with evidenced the secondary structure topology (i.e. red cylinders represent alpha helices). Amino and carboxy terminal ends are indicated. Two disulfide bridges are indicated with yellow sticks. (b) Ribbon diagram of the dimer of sea bass IL-10 with the subunits shown in green and blue. (For interpretation of the references to colour in this figure legend, the reader is referred to the web version of this article.) we reported the models of the monomer and the dimer of sea bass IL-10 (PDB code 2IFK). About $70 \%$ of the residues in each monomer assumes an alpha-helical conformation. Each chain consists of two separate domains, one in the $\mathrm{N}$-terminal region composed of four $\alpha$-helices (A-D), and the other in the $\mathrm{C}$-terminal region composed of two $\alpha$-helices (E and F) in agreement to the structural classification reported by CATH database (Orengo et al., 1997; Pearl et al., 2000) for the reference structure of human IL-10. The internal structure of two domains is quite rigid but the interdomain junction between helices $\mathrm{D}$ and $\mathrm{E}$, bringing the two domains together, is potentially flexible. Two intramolecular disulfide bridges, Cys30-Cys 130 and Cys79Cys136 stabilize each monomer. A potential N-linked glycosylation site, that in human IL-10 is located in the loop between helices $\mathrm{D}$ and $\mathrm{E}$ and is conserved in all mammalian and also in carp, is not present in sea bass.

\section{Discussion}

Our knowledge of cytokines present in teleost fish has dramatically increased in recent years and this animal group is becoming an excellent model among 434 ectothermic vertebrates for studies of their effects on the 435 immune system (Bird et al., 2006; Scapigliati et al., 436 2006a,b). Despite this impressive advancement, the 437 knowledge on the in vivo and in vitro biological activity 438 of fish cytokines is still meager, mainly due to the lack 439 of recombinant peptides or antibodies. To further 440 investigate the evolutionary biology of cytokines in 441 teleost fish, and having molecular probes for some im- 442 munoregulatory genes of sea bass, in this work we 443 considered IL-10 as a putative good candidate to study 444 T-cell activities.

445

Sea bass IL-10 molecule is not highly homologous to 446 its mammalian counterparts (30\% amino acid identity 447 with human IL-10), although the residues and motifs 448 essential for the secondary and tertiary structures are 449 well conserved. The four cysteine residues involved in 450 the formation of intra-molecular disulphide bridges in 451 human IL-10 are conserved, whereas two additional 452 cysteines in the N-terminal region of the molecule are 453 present only in fish sequences. Whether these two 454 residues are important for the IL-10 structure remains to 455 be elucidated. The nucleotide sequence of sea bass IL- 456 10 contains three mRNA instability motifs (ATTTA) 457 which are known to influence mRNA half-life and 458 translational efficiency. This motif, that is believed to 459 play a role in IL-10 regulation (Brown et al., 1996), is 460 present in all vertebrate IL-10 3'-UTR except in rainbow 461 trout (Inoue et al., 2005). The obtained phylogenetic tree 462 shows that sea bass IL-10 grouped in a branch with other 463 teleost sequences, with Tetraodon and Fugu as the most 464 closely related.

465

Real-time PCR analysis detected high levels of 466 constitutive IL-10 expression in HK and gut, as already 467 observed in common carp (Savan et al., 2003). However, 468 this feature appears to be quite variable between fish 469 species, since a very low constitutive expression in all 470 tissues sampled was found in Fugu (Zou et al., 2003) and 471 zebrafish (Zhang et al., 2005), whereas in rainbow trout an 472 intense expression is only in the gills (Inoue et al., 2005). 473 It should be noted that expression of IL-10 is notably 474 elevated in the gut, and we have previously shown this 475 mucosal tissue be particularly rich in T-cells (Abelli et al., 476 1997). Moreover, the IL-10 expression level is very low in 477 the thymus and this could resemble what happens in 478 rodents and human where the naturally occurring CD4+ 479 CD25+ $\mathrm{T}$ regulatory cells (Tregs) that emerge directly 480 from this organ do not produce high IL-10 levels, whereas 481 the $\mathrm{T}$ regulatory type $1(\operatorname{Tr} 1)$ cells, induced by antigen 482 stimulation via an IL-10 dependent process, show high 483 IL-10 and transforming growth factor $\beta$ (TGF- $\beta$ ) 484 (Roncarolo et al., 2006). These observations could be 485 
particularly important when sea bass recombinant IL-10 will become available to investigate in fish its activities, such as the potent effects this cytokine has on human intestinal T-cells (Braunstein et al., 1997).

In close agreement with previous studies, the in vitro stimulation with LPS induced in sea bass HK a high IL10 expression after $4 \mathrm{~h}$, as observed in trout (Inoue et al., 2005), zebrafish (Zhang et al., 2005), carp (Savan et al., 2003), and in human monocytes (Gallagher et al., 2000). After $24 \mathrm{~h}$ of LPS stimulation, a dramatic decrease was observed in sea bass in agreement with results in common carp (Savan et al., 2003), and may suggest that teleost IL-10 may also play a role in the fast processes related to inflammation. However, in a recently published paper, Gonzales et al. (2007) analysed the carp skin inflammatory response after a mechanical injury that mimic infection with ectoparasites and found that no up-regulation of IL-10 was found at time points postup-regulation of IL- $1 \beta$ even if they have data only until 24 h post-injury.

On the other hand, the in vitro treatment of HK leucocytes with the cell mitogen agent PHA-L showed a decrease in IL-10 expression both at $4 \mathrm{~h}$ and $24 \mathrm{~h}$ poststimulation although being not statistically significant. This first observation is in contrast to data in PHAactivated chicken thymocytes (Rothwell et al., 2004) and human PBL (Lagrelius et al., 2006). It remains to be elucidated if this difference could be attributable to the anatomical difference between examined tissues, or to different capability of IL-10 regulation between fishes and other vertebrates.

Sea bass IL-10 3D structure has been predicted by homology modelling procedures and it is resulted as a symmetric homodimer, topologically similar to the structure of interferon- $\gamma$ Each alpha-helical domain is made of two inter-penetrating subunits, forming a V-shaped structure. In fact, the chains of each subunit contribute to both halves of the dimer: helices $\mathrm{E}$ and $\mathrm{F}$ of one monomer form a distinctive six-helix domain with helices $\mathrm{A}^{\prime}-\mathrm{D}^{\prime}$ of the symmetry-related monomer. In addition, helices A, C, $\mathrm{D}, \mathrm{F}^{\prime}$ and $\mathrm{A}^{\prime}, \mathrm{C}^{\prime}, \mathrm{D}^{\prime}$, F of each domain form a classical lefthanded four-helix bundle, found in all crystal structures of the helical cytokine family. The presence of gaps in the alignment made it difficult a complete structural comparison of sea bass IL-10 with the human template. Anyway, superimposition of structurally conserved regions of two structures gives RMSD values of $1.07 \AA$. This value indicates that, despite the low sequence identities, sea bass sequence is well compatible with human IL-10 structure, according with the energy profiles obtained with ProsaII program (data not shown). The comparison of secondary structures suggests that all helices are well conserved

among two species, although few external residues can 538 result added or excluded from the helices (see Fig. 5). The 539 short $3_{10}$ helix, observed in human IL-10 between the 540 helices $\mathrm{D}$ and $\mathrm{E}$ is present also in the sea bass protein. Also 541 the bends, located in helices A, C and F, in the human 542 structure, are conserved even if these are shorter in the sea 543 bass model.

Moreover, we investigated the possible residues of 545 interaction of sea bass IL-10 with its receptor on the basis 546 of the complex between human IL-10 dimer and its 547 receptor molecule (PDB code: $1 \mathrm{~J} 7 \mathrm{~V}$ ) (Josephson et al., 548 2001). The crystal structure of this complex consists of 549 one IL-10 homodimer and two IL-10R1 molecules. Each 550 receptor binds the identical two-fold related surfaces of 551

Table 2 $\mathrm{t} 2.1$

Solvent exposure of IL-10 amino acids interacting with IL-10R in sea bass and human

Amino acids $\%$ $\%$ Solvent exposure Amino in sea bass IL-10 acids

\begin{tabular}{|c|c|c|c|}
\hline Helix A & $\gamma$ & Helix $A$ & \\
\hline PHE 37 & 28.4 & LEU 37 & 14.9 \\
\hline PRO 38 & 67.1 & PRO 38 & 62.6 \\
\hline GLY 39 & 43.9 & ASN 39 & 60.3 \\
\hline LEU 41 & 34.6 & LEU 41 & 42.4 \\
\hline ARG 42 & 69.9 & ARG 42 & 55.9 \\
\hline ARG 45 & 63.5 & ARG 45 & 67.5 \\
\hline ALA 46 & 37 & ASP 46 & 31.2 \\
\hline PHE 48 & 47.9 & PHE 48 & 48.4 \\
\hline THR 49 & 48.8 & SER 49 & 58.6 \\
\hline GLN 52 & 45 & LYS 52 & 40.9 \\
\hline ASP 53 & 62.3 & THR 53 & 58.2 \\
\hline GLU 56 & 63.3 & GLN 56 & 60.6 \\
\hline ALA 57 & 65.7 & MET 57 & 72.3 \\
\hline Loop $A B$ & & Loop $A B$ & \\
\hline ASP 59 & 55.3 & ASP 59 & 63.2 \\
\hline ASP 60 & 92.4 & GLN 60 & 90.8 \\
\hline LEU 61 & 78.5 & LEU 61 & 72.2 \\
\hline ASP 62 & 100.9 & ASP 62 & 105 \\
\hline ALA 63 & 65.1 & ASN 63 & 71.8 \\
\hline ALA 64 & 74.1 & LEU 64 & 61.2 \\
\hline LEU 65 & 93.6 & LEU 65 & 78 \\
\hline Helix F & & Helix $F$ & \\
\hline LYS 159 & 52.7 & LYS 156 & 53 \\
\hline GLY 162 & 81.4 & SER 159 & 70.8 \\
\hline GLU 163 & 50 & GLU 160 & 41 \\
\hline GLY 165 & 53.3 & ASP 162 & 61.5 \\
\hline LEU 166 & 49 & ILE 163 & 40.2 \\
\hline ASN 169 & 49.8 & ASN 166 & 57.6 \\
\hline TYR 170 & 64.5 & TYR 167 & 69.8 \\
\hline GLU 172 & 44.4 & GLU 169 & 56.1 \\
\hline MET 175 & 55.8 & MET 172 & 47.9 \\
\hline ALA 176 & 45.3 & THR 173 & 30.9 \\
\hline GLN 179 & 73.1 & ILE 176 & 69.8 \\
\hline HIS 180 & 56.7 & ARG 177 & 66 \\
\hline
\end{tabular}


IL-10. Residues in the interface are donated from two peptide segments. Moreover, they cluster in two structurally distinct interaction surface, Ia and $\mathrm{Ib}$. Site Ia is centered on the bend in the helix $\mathrm{F}^{\prime}$ and includes the $\mathrm{AB}$ loop, while the site $\mathrm{Ib}$ is located near the $\mathrm{N}$ terminus of helix $\mathrm{A}$ and the $\mathrm{C}$ terminus of helix $\mathrm{F}^{\prime}$. Being the residues of interaction located in the bends present in helices A and $\mathrm{F}$, their different length in human and sea bass models could indicate a possible difference in the complex between this two species. The percentage of solvent exposure for each residue of interaction in human IL-10 and for the related sea bass residues identified on the basis of the alignment was evaluated and the results are reported in Table 2. Some differences can be appreciated in the solvent exposure values of various amino acids (shown in bold during the table) and this should strengthen the possibility that the complex is stabilised in a slight different way in sea bass with respect to human. The knowledge of the putative interaction residues between IL-10 and its receptor could be useful to produce synthetic peptides that, designed on the basis of the structural prediction, should block the site of interaction and provide the possibility to study what happens when the IL-10 signal could not be transduced.

In conclusion, the results we obtained in this work could be useful to increase the knowledge about fish IL-10 even if, so far, a clear anti-inflammatory function remains to be demonstrated.

\section{Acknowledgements}

Authors are indebted to Dr. C. Magugliani and Dr. E. Vela (Nuova Azzurro, Roma) for the supply of fish. The work was partially supported by the European Commission within the project IMAQUANIM (EC contract number FOOD-CT-2005-007103).

\section{References}

Abelli, L., Picchietti, S., Romano, N., Mastrolia, L., Scapigliati, G., 1997. Immunohistochemistry of gut-associated lymphoid tissue of the sea bass Dicentrarchus labrax (L.). Fish Shellfish Immunol. 7, $235-246$.

Altschul, S.F., Gish, W., Miller, W., Myers, E., Lipman, D.J., 1990. Best local alignment search tool. J. Mol. Biol. 215, 403-410.

Barnes, P.F., Chatterjee, D., Abrams, J.S., Lu, S., Wang, E., Yamamura, M., Brennan, P.J., Modlin, R.L., 1992. Cytokine production induced by Mycobacterium tuberculosis lipoarabinomannan. Relationship to chemical structure. J. Immunol. 149, 541-547.

Bird, S., Zou, J., Secombes, C.J., 2006. Advances in fish cytokine biology give clues to the evolution of a complex network. Curr. Pharm. Des. 12, 3051-3069.

Bogdan, C., Vodovotz, Y., Nathan, C., 1991. Macrophage deactivation by interleukin 10. J. Exp. Med. 174, 1549-1555.
Braunstein, J., Qiao, L., Autschbach, F., Schurmann, G., Meuer, S., 602 1997. T cells of the human intestinal lamina propria are high 603 producers of interleukin-10. Gut 41, 215-220.

604

Brown, C.Y., Lagnado, C.A., Vadas, M.A., Goodall, G.J., 1996. 605 Differential regulation of the stability of cytokine mRNAs in 606 lipopolysaccharide-activated blood monocytes in response to 607 interleukin-10. J. Biol. Chem. 271, 20108-20112. 608

Buonocore, F., Randelli, E., Bird, S., Secombes, C.J., Costantini, S., 609 Facchiano, A., Mazzini, M., Scapigliati, G., 2006. The CD8alpha 610 from sea bass (Dicentrarchus labrax L.): cloning, expression and 611 3D modelling. Fish Shellfish Immunol. 20, 637-646.

Costantini, S., Colonna, G., Rossi, M., Facchiano, A.M., 2005. Model- 613 ling of HLA-DQ2 and simulations of its interaction with gluten 614 peptides to explain molecular recognition in celiac disease. J. Mol. 615 Graph. Model. 23, 419-431.

Cunha, F.Q., Moncada, S., Liew, F.Y., 1992. Interleukin-10 (IL-10) 617 inhibits the induction of nitric oxide synthase by interferon-gamma 618 in murine macrophages. Biochem. Biophys. Res. Commun. 182, 619 $1155-1159$.

de Waal Malefyt, R., Yssel, H., de Vries, J.E., 1993. Direct effects of IL-10 621 on subsets of human CD4+ T cell clones and resting T cells. Specific 622 inhibition of IL-2 production and proliferation. J Immunol. 150, 623 4754-4765.

Ding, Y.Z., Fu, S., Zamarin, D., 2003. Interleukin-10, In: Thomson, A.W., 625 Lotze, M.T. (Eds.), The Cytokine Handbook, 4th Edn. Academic 626 Press, London, pp. 603-625.

Facchiano, A.M., Stiuso, P., Chiusano, M.L., Caraglia, M., Giuberti, 628 G., Marra, M., Abruzzese, A., Colonna, G., 2001. Homology 629 modelling of the human eukaryotic initiation factor 5A (eIF-5A). 630 Protein Eng. 14, 881-890.

631

Facchiano, A.M., Costantini, S., Di Maro, A., Panichi, D., Chambery, 632 A., Parente, A., Di Gennaro, S., Poerio, E., 2006. Modelling the 3D 633 structure of WSCI. Probing the reactive site of the inhibitor with 634 two susceptible proteinases, by time-course analysis and molecular 635 dynamics simulations. Biol. Chem. 387, 931-940. 636

Felsenstein, J., 1985. Confidence limits on phylogenies: an approach 637 using the bootstrap. Evolution 39, 783-791.

638

Fiorentino, D.F., Zlotnik, A., Mosmann, T.R., Howard, M., O'Garra, 639 A., 1991. IL-10 inhibits cytokine production by activated macro- 640 phages. J. Immunol. 147, 3815-3822.

Gallagher, G., Dickensheets, H., Eskdale, J., Izotova, L.S., Miroch- 642 nitchenko, O.V., Peat, J.D., Vazquez, N., Pestka, S., Donnelly, R.P., 643 Kotenko, S.V., 2000. Cloning, expression and initial characterisa- 644 tion of interleukin-19 (IL-19), a novel homologue of human 645 interleukin-10 (IL-10). Genes Immun. 1, 442-450. 646

Gonzales, S.F., Huising, M.O., Stakauskas, R., Forlenza, M., Verburg-van 647 Kemenade, B.M.L., Buchmann, K., Nielsen, M.E., Wiegertjes, G.F., 648 2007. Real-time expression analysis in carp (Cyprinus carpio L.) skin: 649 inflammatory response to injury mimicking infection with ectopar- 650 asites. Dev. Comp. Immunol. 244-254.

Guex, N., Peitsch, M.C., 1997. SWISS-MODEL and the Swiss- 652 PdbViewer: an environment for comparative protein modeling. 653 Electrophoresis 18, 2714-2723.

Hubbard, S.J., Campbell, S.F., Thornton, J.M., 1991. Molecular recog- 655 nition. Conformational analysis of limited proteolytic sites and serine 656 proteinase protein inhibitors. J. Mol. Biol. 220, 507-530. 657

Inoue, Y., Kamota, S., Ito, K., Yoshiura, Y., Ototake, M., Moritomo, T., 658 Nakanishi, T., 2005. Molecular cloning and expression analysis of 659 rainbow trout (Oncorhynchus mykiss) interleukin-10 cDNAs. Fish 660 Shellfish Immunol. 18, 335-344.

Jones, S., Thornton, J.M., 1996. Principles of protein-protein interactions 662 derived from structural studies. Proc. Natl. Acad. Sci. 93, 13-20. 663 
Josephson, K., Logsdon, N.J., Walter, M.R., 2001. Crystal structure of the IL-10/IL-10R1 complex reveals a shared receptor binding site. Immunity 14, 35-46.

Julenius, K., Molgaard, A., Gupta, R., Brunak, S., 2005. Prediction, conservation analysis and structural characterization of mammalian mucin-type $O$-glycosylation sites. Glycobiology $15,153-164$.

Kabsch, W., Sander, C., 1983. Dictionary of protein secondary structure: pattern recognition of hydrogen-bonded and geometrical features. Biopolymers 22, 2577-2637.

Lagrelius, M., Jones, P., Franck, K., Gaines, H., 2006. Cytokine detection by multiplex technology useful for assessing antigen specific cytokine profiles and kinetics in whole blood cultured up to seven days. Cytokine 33, 156-165.

Laskowski, R.A., MacArthur, M.W., Moss, D.S., Thornton, J.M., 1993. PROCHECK - a program to check the stereochemical quality of protein structures. J. Appl. Crystallogr. 26, 283-291.

Marabotti, A., D’Auria, S., Rossi, M., Facchiano, A.M., 2004. Theoretical model of the three-dimensional structure of a sugar binding protein from Pyrococcus horikoshii: structural analysis and sugar binding simulations. Biochem. J. 280, 677-684.

Moore, K.W., O'Garra, A., de Waal Malefyt, R., Vieira, P., Mosmann, T.R., 1993. Interleukin-10. Annu. Rev. Immunol. 11, 165-190.

Moore, K.W., de Waal Malefyt, R., Coffman, R.L., O’Garra, A., 2001. Interleukin-10 and the interleukin-10 receptor. Annu. Rev. Immunol. $19,683-765$.

Mosmann, T.R., 1994. Properties and functions of interleukin-10. Adv. Immunol. 56, 1-26.

Mosmann, T.R., Moore, K.W., 1991. The role of IL-10 in crossregulation of TH1 and TH2 responses. Immunol. Today 12, 49-53.

Nielsen, H., Engelbrecht, J., Brunak, S., von Heijne, G., 1997. Identification of prokaryotic and eukaryotic signal peptides and prediction of their cleavage sites. Protein Eng. 10, 1-6.

Orengo, C.A., Michie, A.D., Jones, S., Jones, D.T., Swindells, M.B., Thornton, J.M., 1997. CATH - a hierarchic classification of protein domain structures. Structure 5, 1093-1108.

Pearl, F.M.G., Lee, D., Bray, J.E., Sillitoe, I., Todd, A.E., Harrison, A.P., Thornton, J.M., Orengo, C.A., 2000. Assigning genomic sequences to CATH. Nucl. Acids Res. 28, 277-282.

Pearson, W.R., Lipman, D.J., 1988. Improved tools for biological sequence comparison. Proc. Natl. Acad. Sci. U.S.A. 85, 2444-2448.

Pinto, R.D., Nascimento, D.S., Reis, M.I.R., do Vale, A., dos Santos, N.M.S., 2006. Molecular characterisation, 3D modelling and expression analysis of sea bass (Dicentrarchus labrax) interleukin10. Mol. Immunol. 44, 2066-2075.

Roncarolo, M.G., Gregori, S., Battaglia, M., Bacchetta, R., Fleischhauer, K., Levings, M.K., 2006. Interleukin-10-secreting type 1 regulatory $\mathrm{T}$ cells in rodents and mammals. Immunol. Rev. 212, 28-50.

Rothwell, L., Young, J.R., Zoorob, R., Whittaker, C.A., Hesketh, P., Archer, A., Smith, A.L., Kaiser, P., 2004. Cloning and characterization of chicken IL-10 and its role in the immune response to Eimeria maxima. J. Immunol, 173, 2675-2682.
Saitou, N., Nei, M., 1987. The Neighbour-Joining method — a new 715 method for reconstructing phylogenetic trees. Mol. Biol. Evol. 4, 716 406-425.

Sali, A., Blundell, T.L., 1993. Comparative protein modelling by 718 satisfaction of spatial restraints. J. Mol. Biol. 234, 779-815. 719

Savan, R., Igawa, D., Sakai, M., 2003. Cloning, characterization and 720 expression analysis of interleukin-10 from the common carp, $C y-721$ prinus carpio L. Eur. J. Biochem. 270, 4647-4654. 722

Scapigliati, G., Buonocore, F., Bird, S., Zou, J., Pelegrin, P., Falasco, 723 C., Prugnoli, D., Secombes, C.J., 2001. Phylogeny of cytokines: 724 molecular cloning and expression analysis of sea bass Dicen- 725 trarchus labrax interleukin-1 beta. Fish Shellfish Immunol. 11, 726 711-726.

Scapigliati, G., Costantini, S., Colonna, G., Facchiano, A., Buonocore, 728 F., Bossù, P., Holland, J.W., Secombes, C.J., 2004. Modelling of fish 729 interleukin 1 and its receptor. Dev. Comp. Immunol. 28, 429-441. 730

Scapigliati, G., Buonocore, F., Mazzini, M., 2006a. Biological activity 731 of cytokine: an evolutionary perspective. Curr. Pharm. Des. 12, 732 3071-3081.

Scapigliati, G., Mazzini, M., Buonocore, F., 2006b. Biological activity 734 of cytokines: an evolutionary perspective. Curr. Pharm. Design 12, 735 3071-3081.

Sippl, M.J., 1993. Recognition of errors in three-dimensional struc- 737 tures of proteins. Proteins 17, 355-362. 738

Street, N.E., Mosmann, T.R., 1991. Functional diversity of T lympho- 739 cytes due to secretion of different cytokine patterns. FASEB J. 5, 740 171-177.

Tan, J.C., Indelicato, S.R., Narula, S.K., Zavodny, P.J., Chou, C.C., 742 1993. Characterization of interleukin-10 receptors on human and 743 mouse cells. J. Biol. Chem. 268, 21053-21059.

Thompson, J.D., Higgins, D.G., Gibson, T.J., 1994. Clustal W: im- 745 proving the sensitivity of progressive multiple sequence alignment 746 through sequence weighting, position-specific gap penalties and 747 weight matrix choice. Nucl. Acids Res. 22, 4673-4680.

Wallner, B., Elofsson, A., 2005. All are not equal: a benchmark of 749 different homology modeling programs. Protein Sci. 14, 1315-1327. 750

Windsor, W.T., Syto, R., Tsarbopoulos, A., Zhang, R., Durkin, J., 751 Baldwin, S., Paliwal, S., Mui, P.W., Pramanik, B., Trotta, P.P., et al., 752 1993. Disulfide bond assignments and secondary structure analysis 753 of human and murine interleukin-10. Biochemistry 32, 8807-88015. 754

Zdanov, A., Schalk-Hihi, C., Gustchina, A., Tsang, M., Weatherbee, J., 755 Wlodawer, A., 1995. Crystal structure of interleukin-10 reveals the 756 functional dimer with an unexpected topological similarity to 757 interferon gamma. Structure 3, 591-601.

Zhang, D.C., Shao, Y.Q., Huang, Y.Q., Jiang, S.G., 2005. Cloning, 759 characterization and expression analysis of interleukin-10 from the 760 zebrafish (Danio rerio). J. Biochem. Mol. Biol. 38, 571-576. 761

Zou, J., Clark, M.S., Secombes, C.J., 2003. Characterisation, expres- 762 sion and promoter analysis of an interleukin 10 homologue in the 763 puffer fish, Fugu rubripes. Immunogenetics 55, 325-335. 